S A Journal of Industrial Engineering, Vol 5, No 2, December 1992, pp.1-18

\title{
THE CHARACTERIZATION OF GRINDING FORCES
}

\author{
E.R. FIELDING
}

\author{
SCHOOL OF MECHANICAL ENGINEERING
}

\begin{abstract}
Traditionally the grinding process has been a finishing process and the operating parameters and the results obtained in this mode are well known. However, with the advent of more modern techniques in grinding, there is a need for a greater understanding of the process and in particular a need to be able to predict the forces in grinding. The work reported here is part of an overall programme to study the effects of different dress leads, wheel formulations and metal removal rates on grinding ratios, surface finish and grinding forces. The work so far has led to the development of empirical relationships based on the various factors in the dressing and grinding operations, these empirical relationships are more easily applied than the relationships developed by other researchers that rely on measurements obtained during testing. The work is now being extended to develop a theoretical derivation on the same principles, the implications of which will be discussed in the paper.
\end{abstract}

UNIVERSITY OF THE WITWATERSRAND 


\section{INTRODUCTION}

The cutting characteristics of a grinding wheel will depend on the manner in which the wheel is dressed. Major variations in grinding wheel performance can be obtained by variation of the mechanical finishing of the face of the wheel with the selected dressing tool.

The dressing parameters that affect the cutting capability of the wheel are the dressing infeed applied, the dressing lead and the shape of the diamond. For fast rates of metal removal, large infeeds per dressing pass allied with fast dressing leads would be specified, while for the preparation of a wheel for finish grinding, small dressing feeds in conjunction with low traverse rates would be applied. At the conclusion of dressing, one or two passes can be made without the application of infeed.

Various researchers $[1,2,3,4]$ conclude that the dressing infeed applied does not have as great an affect on wheel pertormance as the dressing lead. Discrepancies in conclusions can be shown to be the result of different diamond shape. Lindsay [1] quantifies the effects of dressing lead and dressing lead on the metal removal capability of the wheel and shows that dressing infeed has the effect of increasing metal removal rate by a $1 / 4$ power while the increase due to the dress lead was a $1 / 2$ power.

Selby [5], Vickerstaff [6], Furuichi [7], Brecker [8] and Fisher [9] broadly agree that the shape of the diamond has a significant effect on the performance of the wheel and that at a given traverse rate, the wheel profile will become increasingly smooth as the wear flat on the diamond increases in size.

It is important to note, therefore, that all dressing conditions are considered, and the manner of their interaction, when specifying dressing conditions.

During grinding the pattern of wheel wear has been shown by Pattinson and Chisholm [2], Grisbrook [10], Rubenstein [11] and Koloc [12] to fall into three distinct phases:

Phase A: intensive wheel wear which is non-linear and related to dressing technique.

Phase B: a linear rate of wear which remains constant for long periods under "good" conditions.

Phase $\mathrm{C}$ : results when the wheel is overloaded and stalls, or excessive vibrations occur; wheel wear occurs due to bond post rupture and whole grits are dislodged.

In Phase B two types of wear may occur, attritious wear or fracture wear and both of these types are accommodated within very small amounts of radial wheel wear. Malkin [13] shows that the size of wear particles is virtually unaffected by wheel dressing conditions and wear rate. Fifty to eighty percent of total wheel wear consisted of bond fracture, almost all the rest of the wear was by grit fracture, but five percent was by attritious wear. This amount of attritious wear, though small, is nevertheless directly related to grinding forces.

In a study of the pattern of grinding forces associated with fine and coarse dressing, Bhateja et al. [14] state that when grinding commences with a freshly dressed wheel, the partially damaged grits are quickly removed, the active grit density decreases and the grinding force components increase from small initial values. For a finely dressed wheel the grinding force components increase to very high values, then subsequently decrease as grinding proceeds. These high values were thought to be caused by the high density of active undamaged grits producing a large number of grinding chips, which associated with insufficient chip clearance leads to the high force levels. In the coarsely dressed wheel, this settling in period is achieved without high 
forces being experienced, probably due to the small number of active grits and the greater degree of initial damage caused by dressing.

After the initial phase of wear and during the secondary wear stage, the wear and force levels show less tendency to change though the rate of change for normal force is greater for the coarsely dressed wheel than for the finely dressed wheel. It would therefore appear that the dressing treatment imparts particular characteristics to a grinding wheel which are retained throughout its useful life.

Grisbrook et al [10] deduce that the increase in normal force, which is at a faster rate than the increase in tangential force, is associated with the increase in the area of contact between the grit and the workpiece. It is postulated that the area of the rubbing end grit $(\mathrm{A})$ is proportional to the wheel wear $(W)$ and the grinding force $(F)$ is proportional of the rubbing end grit in the following manner:

$$
A \propto W^{k} \text { and } F \propto A
$$

Therefore $F \propto W^{k}$ where $k$ is a constant depending on grinding conditions.

Pacitti and Rubenstein [15] state that with the wheel in a stabilized condition (i.e. Phase $B$ ) the ratio of ploughing to cutting grits is constant with time and providing the apparent area of contact between wheel and work is also constant, then the normal force is linearly related to tangential force despite both components varying with grinding time. The normal force is a function of the plateau area/grit and the tangential force is a function of the number of grits in contact. The relationship between normal and tangential force is shown to be

$$
F=(1 / \mu) F T+C
$$

where $\mu$ is the coefficient of friction and $C$ is a complex function of grinding speed, wheel geometry and workpiece properties. Practical testing by Pacitti and Rubenstein yields consistent values for $\mu$ of 0.4 . Thus, it is seen that the change in force levels is determined by the increase of plateau area. During the secondary stage of grinding there is progressing attritious wear and occasional fracture only. In the third stage, there is a large increase in this area which coincides with a rapid increase in force levels. Yoshikawa [16] computed a critical value for plateau area as $8 \%$ of total wheel surface. Malkin [13] reports this critical value as being $3.6 \%$ by weight, but states that variations could occur between 2 and $10 \%$ by weight depending on variations in workpiece material and grinding conditions.

Malkin [13] and Tsuwa [3] adopt a common approach to the characterization of grinding forces. They reason that the tangential and normal forces each consist of two components as follows

$$
\begin{aligned}
& F_{T}=F_{T C}+F_{T F} \\
& F_{N}=F_{N C}+F_{N F}
\end{aligned}
$$

where the term $\mathrm{C}$ indicates the cutting component and the term $\mathrm{F}$ the friction component. The system is illustrated in Fig. 1.

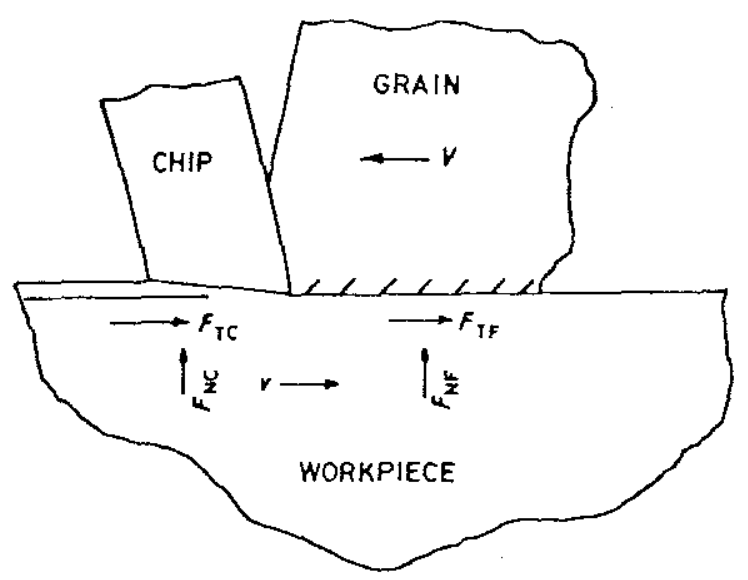

Figure 1. Distribution of force components 
In developing formulae to predict grinding forces Malkin [13] uses values for the coefficient of friction $\mu$, average contact pressure $P$, and wear flat area $\alpha_{r}$ in the following manner:

$$
\begin{aligned}
& F_{T}=F_{T C}+\mu P \alpha_{r} \\
& F_{N}=F_{N C}+P \alpha_{r}
\end{aligned}
$$

When grinding forces were plotted against wear flat area, values for $F_{N C}$ and FTC were determined as the values when wear flat area was equal to zero. It was possible to measure wear flat area and hence, values for average contact pressure and coefficient of friction were determined. The value of the coefficient of friction determined was 0.61 which is rather high when compared with 0.3-0.5 (Tsuwa et al [17]) and 0.41 (Pacitti and Rubenstein [15]).

Tsuwa et al [17] developed empirical formulae as follows:

$$
\begin{aligned}
& F T=K T V^{-0.75} v^{0.75} t^{0.83} B^{1.0}+\mu K_{N F} 1_{s} B \varepsilon \\
& F_{N}=K V^{0.78} v^{0.78} t^{0.78} B^{1.0}+K N t_{s} B \varepsilon \\
& \text { where } \quad \begin{aligned}
s & =\text { length of arc } \\
B & =\text { grinding width } \\
\varepsilon & =\text { percent wear flat area }
\end{aligned}
\end{aligned}
$$

The value of $\mu$ computed by Tsuwa et al was 0.4 . Thus several researchers have successfully developed formulae to predict grinding forces, but in predicting these forces, either the rate of increase of wear flat area and average contact pressure have to be determined, or in the other case; the length of contact arc. None of these values are readily available to engineers without calculation or experiment. To overcome this difficulty, formulae have been developed which utilize only commonly specified parameters in the grinding process.

\section{ANALYSIS AND DISCUSSION OF RESULTS}

The problem of the characterization of grinding forces has been split into two parts. The first was to develop an empirical relationship based on commonly specified grinding parameters and then to develop the theoretical model of the process.

The work to develop the empirical model was carried out on a cylindrical grinder which was modified to give infinitely variable wheelspeeds up to $60 \mathrm{~m} / \mathrm{s}$. Modifications were also made to the table traversing mechanism so that accurate and consistent dressing speeds could be obtained. Grinding forces were measured using Kistler load cells incorporated into the work holding centers.

All grinding tests were carried out in the plunge grinding mode at metal removal rates of 4,8 and $16 \mathrm{~mm}^{3} / \mathrm{mm} / \mathrm{sec}$. During testing wheel wear measurements were taken after $0.5 \mathrm{~mm}$ on diameter was removed, normal and tangential forces were continually monitored. A minimum amount of $6 \mathrm{~mm}$ on diameter $\left(25000 \mathrm{~mm}^{3}\right)$ was removed except when grinding conditions did not allow grinding to this stage. The following variables were kept constant during testing:

- workspeed

- wheel specification

- workpiece specification

* dressing tool and dressing wheelspeed

During testing the following parameters were varied and their effect upon force levels studied: 
* dressing tool traverse rate (dress lead)

* wheelspeed during grinding

- metal removal rate

From the results of the tests graphs of normal and tangential force were prepared. A typical plot is shown in Fig. 2. From these tests values for the forces at $500 \mathrm{~mm}^{3}$ and $15000 \mathrm{~mm}^{3}$ were extracted and statistically tested using analysis of variance techniques to determine the significance of the parameters of dress lead, wheelspeed and metal removal rate, on grinding forces. Composite graphs were also prepared to illustrate a range of conditions, examples of these graphs are shown in Figs. 3 to 5 .

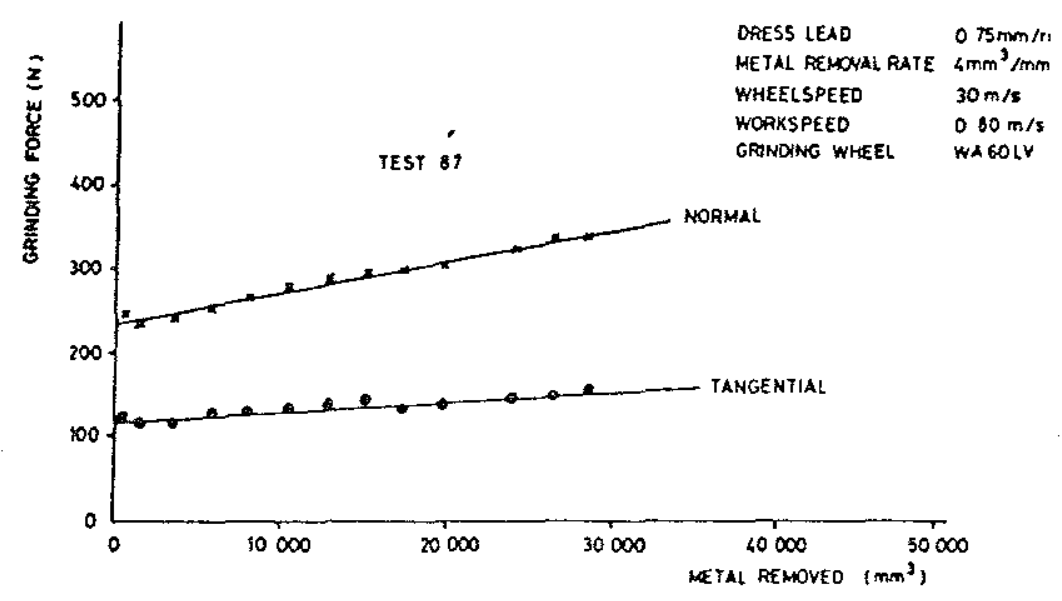

Figure 2. Grinding forces (Test No. 87)

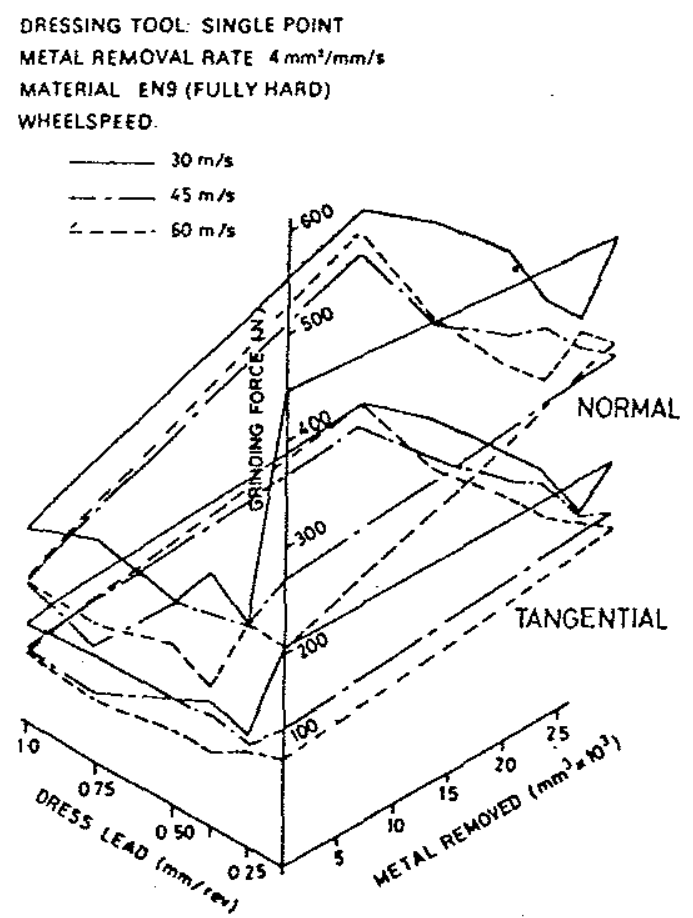

Figure 3. Grinding Forces 


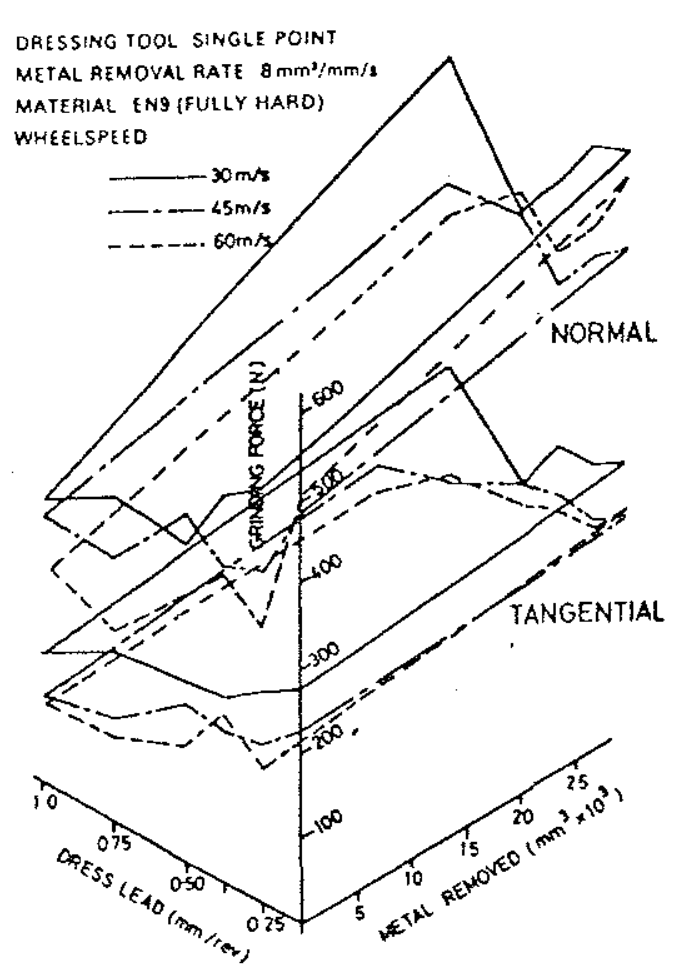

Figure 4. Grinding Forces

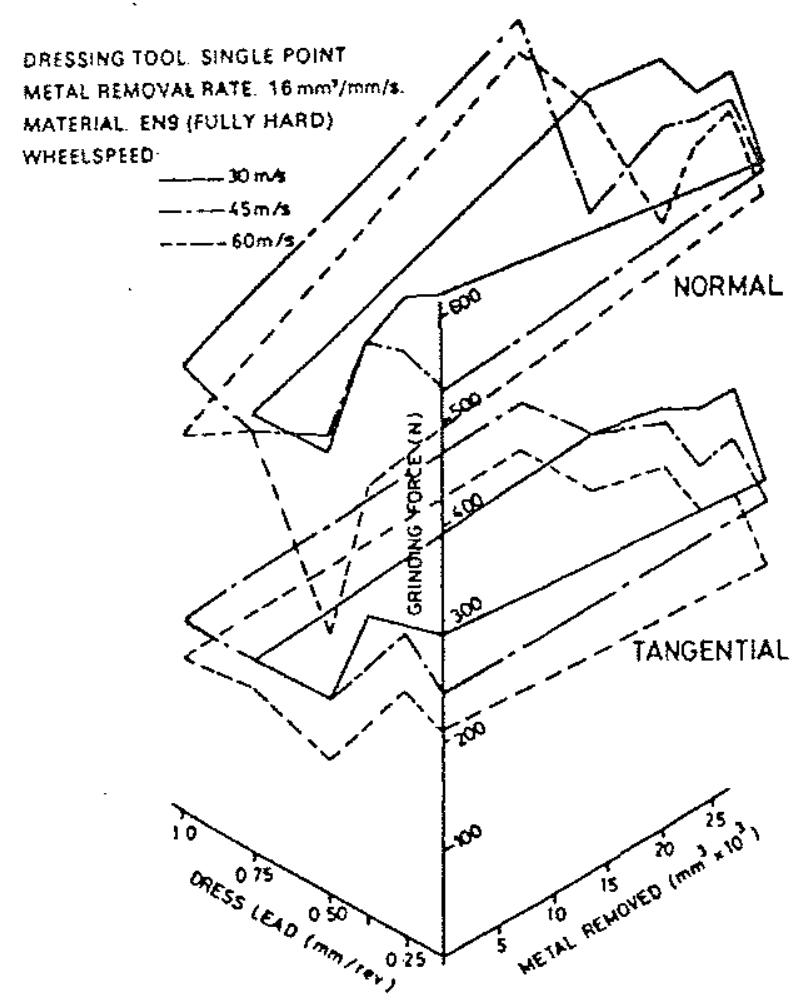

Figure 5. Grinding Forces 
The analysis of variance $3^{3}$ factorial design was carried out based on 26 degrees of freedom with the three factor interaction at 8 degrees of freedom being used to evaluate the error mean square. $F$ tests were then used to decide the level of significance of the main effects and interactions. The completed analysis is shown in Table 1.

\begin{tabular}{|c|c|c|c|c|c|c|}
\hline & $\begin{array}{c}\text { Bane } \\
\text { norma! } \\
\text { force }\end{array}$ & $\begin{array}{c}\text { Normal } \\
\text { force } \\
\text { (5000 mn') }\end{array}$ & $\begin{array}{l}\text { Normal } \\
\text { force } \\
\left.\text { \{15000 } \mathrm{mm}^{3}\right\}\end{array}$ & $\begin{array}{c}\text { Bese } \\
\text { tengentisl } \\
\text { force }\end{array}$ & $\begin{array}{c}\text { Tangential } \\
\text { foree } \\
\left(500 \mathrm{~mm}^{3}\right)\end{array}$ & $\begin{array}{c}\text { Tangential } \\
\text { force } \\
\left.\text { (is } 000 \mathrm{~mm}^{3}\right)\end{array}$ \\
\hline \multicolumn{7}{|l|}{$\begin{array}{l}\text { Main efects } \\
\text { Mels! rrmaral rate (H) }\end{array}$} \\
\hline $\begin{array}{l}L_{x} \\
Q_{x}\end{array}$ & $\begin{array}{l}400-77 \cdots \cdots \\
3.17\end{array}$ & $\begin{array}{l}60.97 \times 4 \\
008\end{array}$ & $\begin{array}{r}182-492+0 \\
002\end{array}$ & $\begin{array}{l}268.14 \cdots * * \\
2 \cdot 43\end{array}$ & $\begin{array}{r}86.45 .40 \\
0.03\end{array}$ & $\begin{array}{c}137.33 \cdots \cdots \\
0-08\end{array}$ \\
\hline Wheelspeed (n) & & & & & & \\
\hline 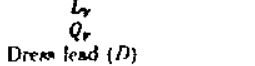 & $\begin{array}{l}20-84 \cdots * \\
0.05\end{array}$ & $\begin{array}{l}0.67 \\
0.01\end{array}$ & $9810 *$ & $\begin{array}{l}47 \cdot 16^{* \cdots *} \\
024\end{array}$ & $\begin{array}{l}8.899^{\circ 0} \\
0.57\end{array}$ & $\begin{array}{l}30-26 * * * \\
0-48\end{array}$ \\
\hline $\begin{array}{c}\text { Drema ead }(J\}) \\
L_{0} \\
Q_{0}\end{array}$ & $\begin{array}{l}48.26 \cdots \\
10.37 \cdots\end{array}$ & $\begin{array}{l}563^{* 1} \\
2 \cdot 81\end{array}$ & $\begin{array}{l}15 \cdot 75 * * * \\
3 \cdot 14\end{array}$ & $\begin{array}{l}52 \cdot 97, \ldots * \\
7 \cdot 44^{\circ}\end{array}$ & $\begin{array}{l}12 \cdot 31 \cdot \cdots 0 \\
0-83\end{array}$ & $\begin{array}{c}26-90 \cdots \\
1-11\end{array}$ \\
\hline \multicolumn{7}{|l|}{ Two.fartor interaction } \\
\hline $\begin{array}{l}L_{z} L_{v} \\
Q_{u} L_{v}\end{array}$ & $1 \cdot 17$ & $0-00$ & 0,30 & $\begin{array}{l}60.0600 \\
2.52\end{array}$ & $\begin{array}{l}2 \infty 0 \\
0 \infty\end{array}$ & $\begin{array}{l}3-77^{\circ} \\
0.81\end{array}$ \\
\hline $\begin{array}{l}Q_{M} L_{\nu} \\
L_{H} Q_{y}\end{array}$ & $\begin{array}{l}3 \cdot 22 \\
0-05\end{array}$ & $\begin{array}{l}002 \\
0.02\end{array}$ & 0.00 & $0+2$ & $0-02$ & $0-\infty$ \\
\hline$Q_{w r}$ & $0-07$ & 004 & 020 & 107 & 000 & 084 \\
\hline $\begin{array}{l}L_{M} L_{D} \\
Q_{A} L_{D}\end{array}$ & $\begin{array}{l}886^{\circ *} \\
1.91\end{array}$ & $\begin{array}{l}109 \\
0.16\end{array}$ & $\begin{array}{l}1.36^{\circ} \\
1.72\end{array}$ & $\begin{array}{l}1860.40 \\
2.55\end{array}$ & $\begin{array}{l}2 \cdot 50 \\
0.43\end{array}$ & $\begin{array}{l}10-092 * \\
108\end{array}$ \\
\hline $\begin{array}{l}L_{\text {W }} Q_{0} \\
Q_{\text {M }} Q_{0}\end{array}$ & $\begin{array}{l}4.32^{\circ} \\
163\end{array}$ & $\begin{array}{l}188 \\
5 \cdot 26^{* *}\end{array}$ & $\begin{array}{l}1 \cdot 21 \\
0.13\end{array}$ & $\begin{array}{l}3977^{\circ} \\
1.29\end{array}$ & $\begin{array}{l}0-33 \\
3-67^{\circ}\end{array}$ & $\begin{array}{l}0.28 \\
0.02\end{array}$ \\
\hline$L_{0} L_{\infty}$ & & 070 & 006 & 0.19 & 0003 & 0.18 \\
\hline$Q_{r} L_{D}$ & 000 & 001 & 001 & 008 & $0-03$ & 007 \\
\hline $\begin{array}{l}i_{P} Q_{D} \\
P_{p} Q_{D}\end{array}$ & $1 \cdot 36$ & 1.17 & 0.22 & 0.99 & 1.84 & $0-33$ \\
\hline$P_{r} Q_{p}$ & 5.5900 & 0.32 & 0.23 & $8-44^{\circ}$ & 049 & \\
\hline Three-factor interactions & 875.38 & 5070.54 & 212975 & 25804 & $672 \cdot 47$ & 471.88 \\
\hline Total & 17818.44 & $17287 \cdot 27$. & 18827.97 & 42505 & $3324 \cdot 33$ & $4082-89$ \\
\hline
\end{tabular}

$\cdots$ highly aignificant. $\cdots$ oignificant. $\cdot$ probebly aignificant.

Table 1. Summary of analysis of variance (Test Series 1)

\section{i) Variations in grinding force due to changing dress lead}

Statistical testing shows that the dress lead has a significant affect on both the values of normal and tangential forces at the commencement of grinding. As the dress lead is increased to give a more open wheel the grinding forces are reduced. In addition to the main effect of dress lead it is to be noted that there is an interaction between the dress lead and metal removal rate. As the metal removal rate is increased in combination with higher dress leads, the grinding forces will be at a lower level. This can be explained by the fact that at higher metal removal rates the wheel quickly breaks down the surface and produces sharp cutting edges and hence lower forces.

As grinding proceeds the results show that the dress lead has a less complex effect on forces, which is still highly significant. The net result is that an increase in dress lead will give lower grinding forces owing to the more open and sharper wheel.

ii) The effect of wheelspeed on grinding forces

Test results show that for each increase in wheelspeed there is a subsequent reduction of both normal and tangential forces. This reduction of force levels can be explained by the reduction of chip thickness that results from an increase in wheelspeed. Chip thickness $t_{\max }$ can be calculated using the equation proposed by Reichenbach et al [18]:

$t_{\max }=\left[\frac{4 v}{V C r} \sqrt{\left(\frac{d}{D}+\frac{d}{D w}\right)}\right]^{0.5}$ 
where

$$
\begin{aligned}
& v=\text { workspeed } \\
& V=\text { wheelspeed } \\
& C=\text { number of effective grits } \\
& r=\text { width to depth ratio } \\
& d=\text { depth of cut } \\
& D=\text { wheel diameter } \\
& D_{w}=\text { workpiece diameter }
\end{aligned}
$$

If can be deduced from the above expression that the maximum chip thickness is inversely proportional to the square of wheelspeed. The effect is illustrated in Fig. 6. Peklenik [19] observes that an increase in wheel-speed produces an effective increase in the effective distance between cutting points, which will tend to reduce the value of the factor $C$ in eqn. (1) and tend to increase the value of chip thickness.

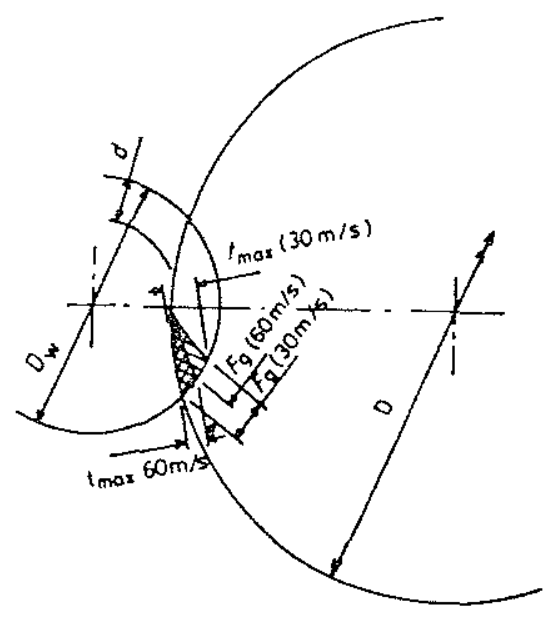

Figure 6. The effect of wheelspeed on chip thickness

A reduction in chip thickness will lead to a reduction in the load per grit, hence lower tangential forces and reduced power drawn. The reduction of maximum chip thickness will also lead to lower contact area and hence a lower normal force.

iii) The effect of metal removal rate on grinding force

An examination of Table 1 shows that metal removal rate has an important effect upon the level of grinding force. As the metal removal rate is increased, the maximum chip thickness increases and this leads to higher values of both normal and tangential forces.

\section{THE EMPIRICAL PREDICTION OF FORCES}

The results of testing confirm that metal removal rate, wheelspeed and dress lead significantly effect the levels of normal and tangential forces. In addition, it is generally agreed $[10,15]$ that as grinding proceeds there is a build up of wear flats that lead to an increase in normal force. This increase in wear flat areas is dependent on the initial condition imparted to the wheel, the metal removal rate and the metal removed, in other words there is a time dependency. 
From a review of the literature and an examination of the test results, it was felt that it was reasonable to assume that the forces at any time during grinding could be expressed in the form:

$$
\begin{aligned}
& F_{N}=K V_{s}{ }^{x} \cdot M^{y} \cdot D^{z} \\
& \text { where } \quad F_{N}=\text { normal force } \\
& V_{S}=\text { wheelspeed } \\
& M=\text { metal removal rate } \\
& D=\text { dress lead } \\
& K=\text { constant } \\
& x, y, z=\text { regression coefficients }
\end{aligned}
$$

The constant $K$ represents the base force, this force has no physical significance but it can be regarded as a start point from which all other forces can be derived.

The constant is derived by analyzing each test to give expressions for normal force in the form $y=m x+c$ (linear regression) as shown in Fig. 2. The value for $c$ defines the initial force under those conditions. This is the force at the commencement of grinding. The constant $m$ defines the

\begin{tabular}{|c|c|c|c|c|c|c|c|c|c|c|c|c|c|c|c|c|}
\hline \multirow{2}{*}{$\begin{array}{l}\text { Whaned } \\
\text { apend } \\
\text { (m/n) }\end{array}$} & \multirow{2}{*}{ 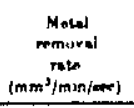 } & \multicolumn{3}{|c|}{ 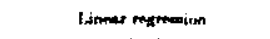 } & \multicolumn{3}{|c|}{ Rxponmenual surve Ac } & \multicolumn{3}{|c|}{ Powrer ourro As: } & \multirow[b]{2}{*}{ 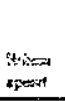 } & \multirow{2}{*}{ 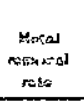 } & \multirow[b]{2}{*}{ Corezent } & \multicolumn{2}{|c|}{ Pityremed } & \multirow[b]{2}{*}{$\begin{array}{l}\text { Complatum } \\
\text { numpterent }\end{array}$} \\
\hline & & & Nlope & $\begin{array}{l}\text { Comptation } \\
\text { mothirmnt }\end{array}$ & Constunt & Exponent & $\begin{array}{l}\text { Contellation } \\
\text { opeffiement }\end{array}$ & Comatent & Panpoment & 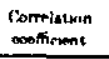 & & & & 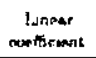 & 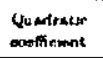 & \\
\hline$m$ & 4 & $3779 \cdot 32$ & $-2 x \cos$ & tromo & 3) & $-\operatorname{nnn}$ & Dד & $8 \times 0 \cdot 41$ & $-0.35 x$ & $07 n$ & 30 & 4 & $\sec 10$ & -113001 & $x=78$ & $\mathrm{Om}$ \\
\hline 31) & K & W4:GK & $-123 \cdot 28$ & 1577 & $44+75$ & $-4+314$ & $07 A$ & 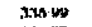 & $-0+64$ & D.m & $x$ & A & $\sec \& 8$ & $-3 \operatorname{sen}$ & $\cos 34$ & $9 \times 7$ \\
\hline 30 & is & $N(\alpha) \times B$ & $-293 \cdot 65$ & $18 \times 7$ & מIX-91 & - 0.0. & $17 \mathrm{NT}$ & $\operatorname{sen} 07$ & -0.24 & 0.93 & $\mathbf{x}$ & in & Mis 74 & $-\operatorname{sen}$ & axi y3 & $1 \times \infty$ \\
\hline 40 & 4 & $2 \pi, 6-41$ & $-17 * * 2$ & trot & $3+x \cdot 79$ & - otrass & 0.457 & 24017 & -0.572 & $+\infty$ & 48 & 4 & 357.0 & $-4,2 \pi, 3]$ & $2 \pi y+4$ & $0-90$ \\
\hline 48 & * & $34 \cdot 12$ & -82.24 & $(2+8)$ & $3 x 010$ & $-\operatorname{ct} 250$ & $0 \leqslant 0$ & $2901 \times 3$ & -0.4 & 1773 & 45 & s & 57404 & $-M z \cdot \Delta s$ & 9070 & arm \\
\hline \& & 10 & 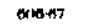 & -204013 & $1+9.7$ & AIS.MA & $-4 \$ 412$ & nros & $42 \times 25$ & $-v 172$ & (n) & 45 & 18 & as? & $-330.31)$ & 137.15 & 0.98 \\
\hline$\infty$ & 4 & $24 \mathrm{~cm} 7$ & $-1 \mid 1+1 k)$ & $12 \times 2$ & 26.741 & - C)MA & $0 \times 1$ & 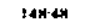 & -0.244 & $\operatorname{lon} 7$ & no & 4 & $27 \times-97$ & $-2010 \mathrm{~s}$ & 10019 & עינד \\
\hline 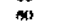 & " & $3 M-21$ & -117.61 & orm & $2 M+4 z$ & - cossum & oms & $2 m>24$ & $-\approx i 77$ & $0 \times 2$ & a) & $x$ & sw-75 & $-3 \times 10$ & 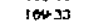 & Qyz \\
\hline 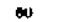 & 16 & 4Den GN & - Horkz & Itss & 49471 & 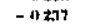 & OAS & 3 & -8100 & $\cos x$ & *1 & 16 & 50077 & $-(x) \geq k$ & $2 \Delta s 6 t$ & $1+\infty$ \\
\hline
\end{tabular}
rate of increase of force.

The initial forces obtained were then segregated by metal removal rate and wheelspeed (see Table 2). From this data initial forces at zero dress lead were established as shown in Fig. 7. This is a logical value, as this would be the value obtained if a perfectly smooth wheel were applied, even though a wheel prepared in this manner would be able to sustain cutting for only a short length of time.

Table 2. Regression analysis of initial normal force 


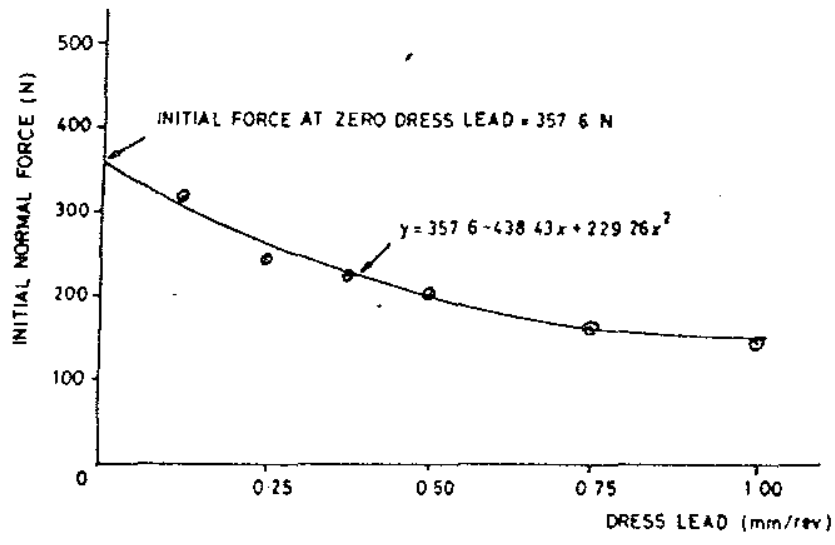

Figure 7. Initial normal force versus dress lead

When the initial forces at zero dress lead are then sorted according to wheelspeed and plotted against metal removal rate (Fig. 8), values of the intercepts were combined to derive an expression for the base force in the form $F_{N B}=607.86-6.99 V_{s}$. It would be possible, though tedious, to continue in this manner to build up a complete expression for the forces.

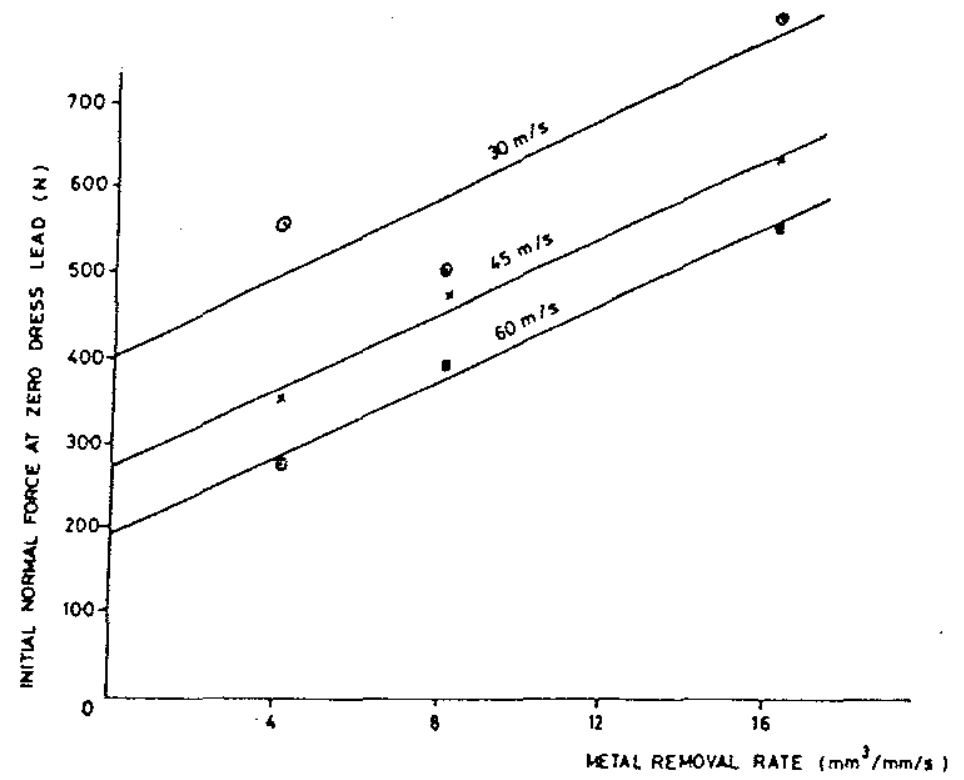

Figure 8. Base normal forces 
However using multiple linear regression techniques, which included both the main effects and interactions, the initial normal force was calculated to be

$$
F_{\mathrm{NI}}=343.09 \mathrm{Vs}^{-0.29} \mathrm{M}^{0.597} \mathrm{D}^{-0.219} \text { Newtons }
$$

In a somewhat similar manner the force at $15000 \mathrm{~mm}^{3}$ of metal removed was calculated to be

$$
F_{\mathrm{NR}}=343.09 \mathrm{Vs}^{-0.29} \mathrm{M}^{0.524} \mathrm{D}^{-0.148} \text { Newtons }
$$

As the pattern of forces are known to be linear, to obtain an expression for grinding force at any point of time until the conclusion of steady state grinding, it is necessary to compute the increase in force per unit volume of metal removed and combine this with the expression for initial normal force as follows

$$
F_{N}=F_{N 1}+(M R / K)\left(F_{N R}-F_{N 1}\right) \text { Newtons }
$$

$$
\text { where } \quad \begin{aligned}
& F_{N}=\text { normal force } \\
& F_{N I}=\text { initial force } \\
& F_{N R}=\text { force at } 15000 \mathrm{~mm}^{3} \text { removed } \\
& M R=\text { metal removed } \\
& K \quad=15000
\end{aligned}
$$

In a similar manner the expressions for tangential force were computed as follows

$$
\begin{gathered}
F_{T I}=290.83 \mathrm{~V}^{-0.503} M^{0.516} D^{0.244 \text { Newtons }} \\
F_{T R}=355.27 \mathrm{Vs}^{-0.486} \mathrm{M}^{0.454} \mathrm{D}^{-0.205} \text { Newtons }
\end{gathered}
$$

and

$$
F_{T}=F_{T I}+(M R / K)\left(F_{T R}-F_{T 1}\right) \text { Newtons }
$$

Using values predicted using eqn. (4) and comparing these in the ratio of Normal force (predicted)

Normal force (actual)

deviation of 0.09 . For a predicted value of 300 Newtons the $95 \%$ confidence limits for test results are between 253 and 363 Newtons. The equivalent results for tangential force were of the same order. The results are shown graphically in Figs. 9,10 and 11 .

These equations can be compared with those derived by other researchers, notably Tsuwa [3] and Malkin [13], and it will be seen that basic points of similarity occur. Both researchers concluded that there is a threshold force, Malkin determined the value and used it as a constant, while Tsuwa derived the expression quoted earlier. The main point of difference between Tsuwa's work and that reported here is that only one dress lead was used to determine the force equations; it is felt by the author that this factor must be incorporated for greater applicability. 
WHEELSPEEO $45 \mathrm{~m} / \mathrm{s}$

METAL REMOVAL RATE $4 \mathrm{~mm}^{3} / \mathrm{mm}$ 'sec

- DEST RESULTS

-.. PAEDICIEO FOACE

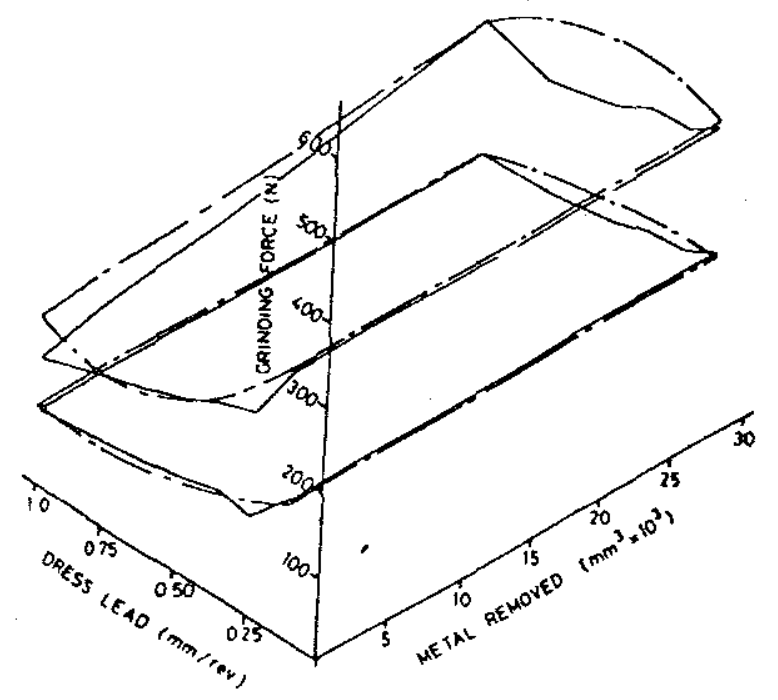

Figure 9. Predicted and actual forces

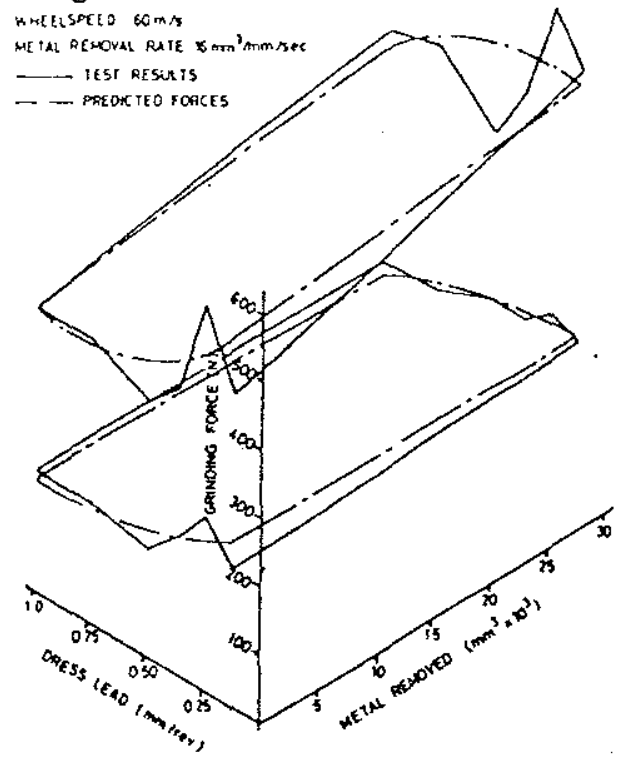

Figure 10. Predicted and actual forces

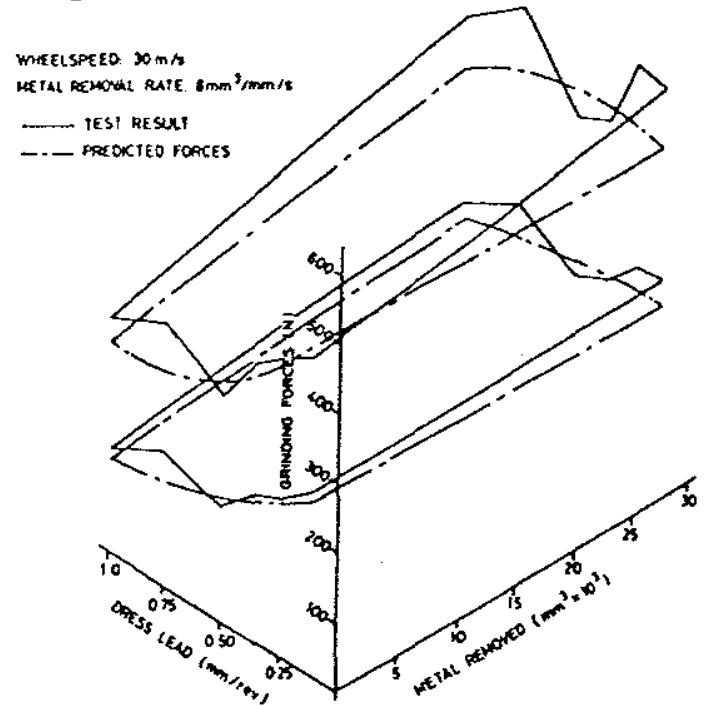

Figure 11. Predicted and actual forces 
Further testing has shown that the factors of wheel grade and workspeed can be introduced into the equation without altering the basic form of the expression.

\section{DERIVATION OF THE THEORETICAL MODEL}

Simulation of the grinding process is difficult owing to the complexity of the process. Traditionally simulation models have been developed along two lines; the first concentrated on the development of a theoretical model and experimental verifaction or secondly the data was used to generate empirical formulae, which were verified by correlation with the data. Both methods rely on probability functions to predict the random behaviour of the process. The development of the probability functions has proved to be very difficult due to the underlying interactions of the parameters concerned.

In grinding the geometry of the cutting edges are unknown and randomly distributed on the wheel surface. Peklenik [20] observed that the grain size on a grinding wheel varied significantly with a standard deviation of approx. $25 \%$ of nominal grain size. Bual [21] proposed a simple random model in which the asperities and valleys of the abrasive surface were simulated by rods of various heights having a truncated normal distribution. The sample distributions of the distances between asperities and the depth of penetration were then obtained. McAdams [22] studied the cutting performance in belt grinding using Markov chain theory. Yoshikawa and Sata [23] simulated the grinding process using Monte Carlo methods, the transfer function in this case was obtained by considering simulated and experimental profiles as input and output respectively. The results showed that the transfer function was amplified at lower frequencies.

Peklenik [20] investigated the grinding process as a linear system with random input and output, in this case the cutting profile of the wheel was taken as a stationary stochastic process. Deutsch and Wu [24] developed an auto regressive moving average model to represent the grinding wheel profiles for various combinations of sampling parameters. They concluded that a large number of observations were needed to increase the confidence associated with the estimated parameters.

In most of the analyses cited the object was to simulate the grinding wheel profile by considering the probability density function of the grits on the surface of the grinding wheel, it may be concluded that this function is required for the development of a simulation program. It is used to model the dynamic process of the active grits, i.e. how many grits are active at any given time, how many grits are lost and what is the current profile of the grits. The profile in particular will determine the depth of cut and also the rate of wear.

To provide a basis for simulation studies, it was decided to study the behaviour of the wheel surface using cluster overcut fly grinding (COFG). In this method all the grains on the surface of a dressed wheel except those in a small $3 \mathrm{~mm} \times 3 \mathrm{~mm}$ area on the wheel face are removed. As an alternative sections of the wheel may be removed, mounted in a dummy wheef and then dressed.

Grinding using this method produces a series of sets of scratches along the specimen surface. Transverse traces of each set of scratches using a Talysurf enable direct determination of the number of active grits, and examination of successive sets of scratches enable a determination of wear rate to be made. The method is shown in Fig. 12 . 


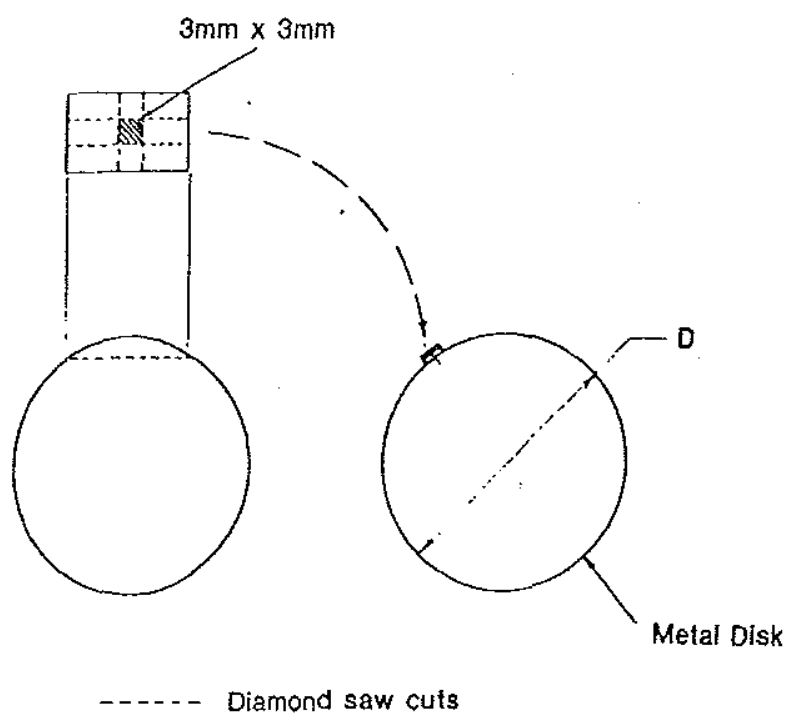

Figure 12. Removal of grinding wheel test pieces

This method for determining the number of active grits and grit wear is superior to other methods, including single grit studies, as it utilizes a sample of the entire wheel surface. In this way the interaction of adjacent grits, the role of the bond and the actual spacing of the active cutting points are all considered. The fact that COFG grinding is intermittent is not considered to be important.

During testing 16 experiments were performed using a $2^{n}$ Factorial design with 4 variables, metal removal rate, wheel grade, grit size and dress lead being set at two levels. Experiments were carried out in a randomly ordered sequence. A sample of the results obtained by this method are shown in Table 3 and Figs. 13 and 14. When all the data was analysed it was noted that two distinct regions of wear (Phase A and $B$ ) were apparent. This followed the trends noted by other researchers $[2,10,11,12]$ and is illustrated in Figure 15.

\begin{tabular}{ccrr}
\hline $\begin{array}{llr}\text { STATION } \\
\text { NUMBER }\end{array}$ & $\begin{array}{l}\text { ACTIVE } \\
\text { GRITS }\end{array}$ & $\begin{array}{r}\text { WEAR } \\
\text { RATE }\end{array}$ & $\begin{array}{r}\text { CUM. } \\
\text { WEAR }\end{array}$ \\
\hline 1 & 21 & 0.00 & 0.00 \\
2 & 20 & 28.53 & 28.53 \\
3 & 18 & 25.92 & 54.45 \\
4 & 15 & 22.13 & 76.59 \\
5 & 14 & 19.97 & 96.56 \\
6 & 14 & 19.79 & 116.34 \\
7 & 14 & 19.79 & 136.13 \\
8 & 10 & 14.13 & 150.26 \\
9 & 8 & 11.31 & 161.57 \\
10 & 8 & 11.31 & 172.88 \\
11 & 6 & 8.48 & 181.36 \\
12 & 6 & 8.48 & 189.84 \\
13 & 5 & 7.07 & 196.90 \\
14 & 5 & 7.07 & 203.97 \\
15 & 4 & 5.65 & 209.62 \\
\hline
\end{tabular}

Table 3. Active grits and wear rate (Test 2) 
Casual examination of the data does not reveal the fact that they describe a complex distribution of the form shown in Figure 16. This distribution is best described by the Complex Weibull Distribution. Analysis of the data in this manner shows that two linear relationships can be derived for the data and two sets of Weibull parameters established. This is illustrated in Figure 17. The distributions obtained from the analysis of wear results were then combined to give a model whereby a specific grinding time could be input into the function and a predicted wear calculated. Statistical testing shows that the most significant variables affecting wheel wear are the dressing lead and infeed or metal removal rate. The variables grit size and wheel grade are not significant on the wear of the grinding wheel. This confirms the results obtained in the earlier phase of testing.

On completion of this phase of activities the wear and force predictions will be checked using whole wheels in a series of experiments.

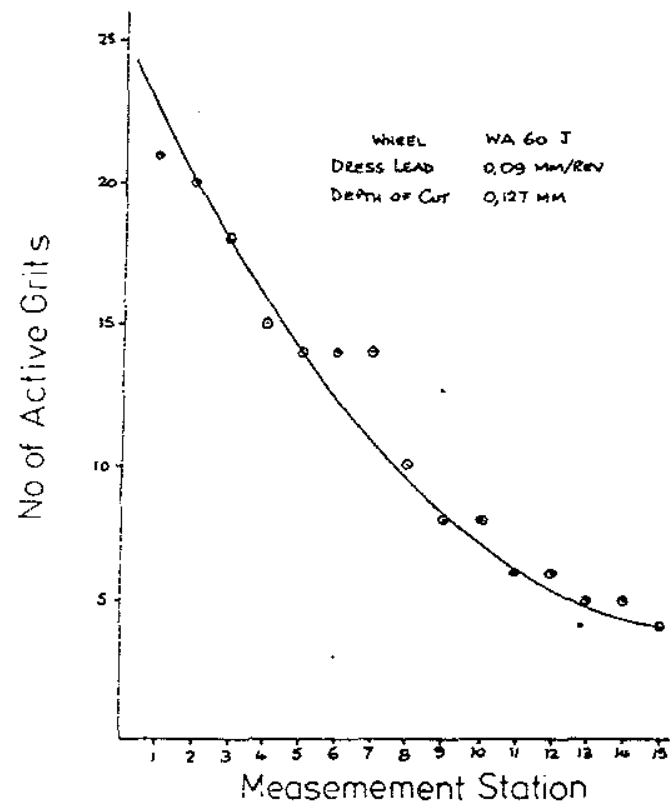

Figure 13. Variation of active grits

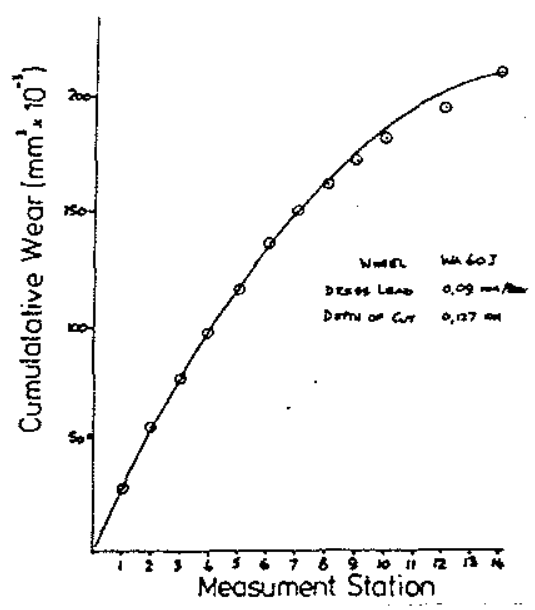

Figure 14. Wear Rate 


$$
-16-
$$

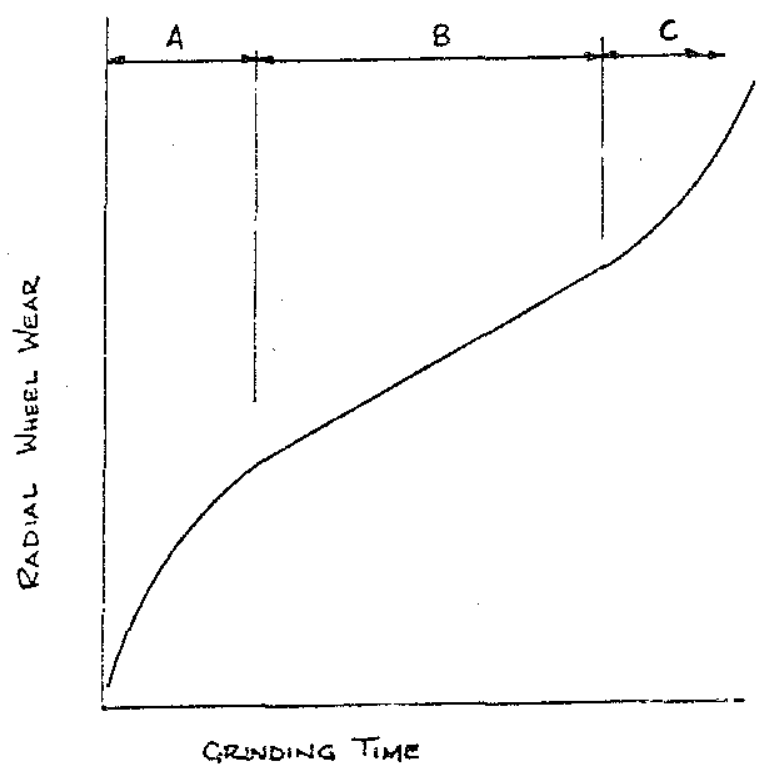

Figure 15. Pattern of wheel wear during grinding

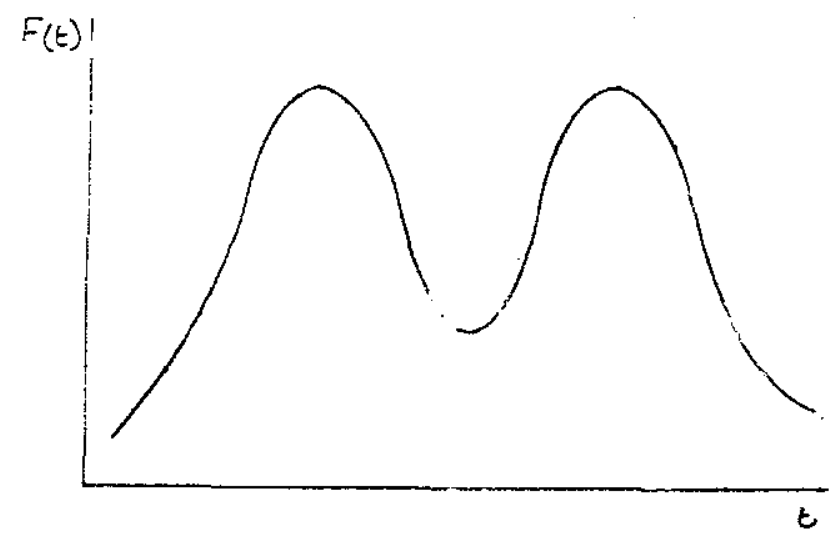

Figure 16 Wear frequency distribution

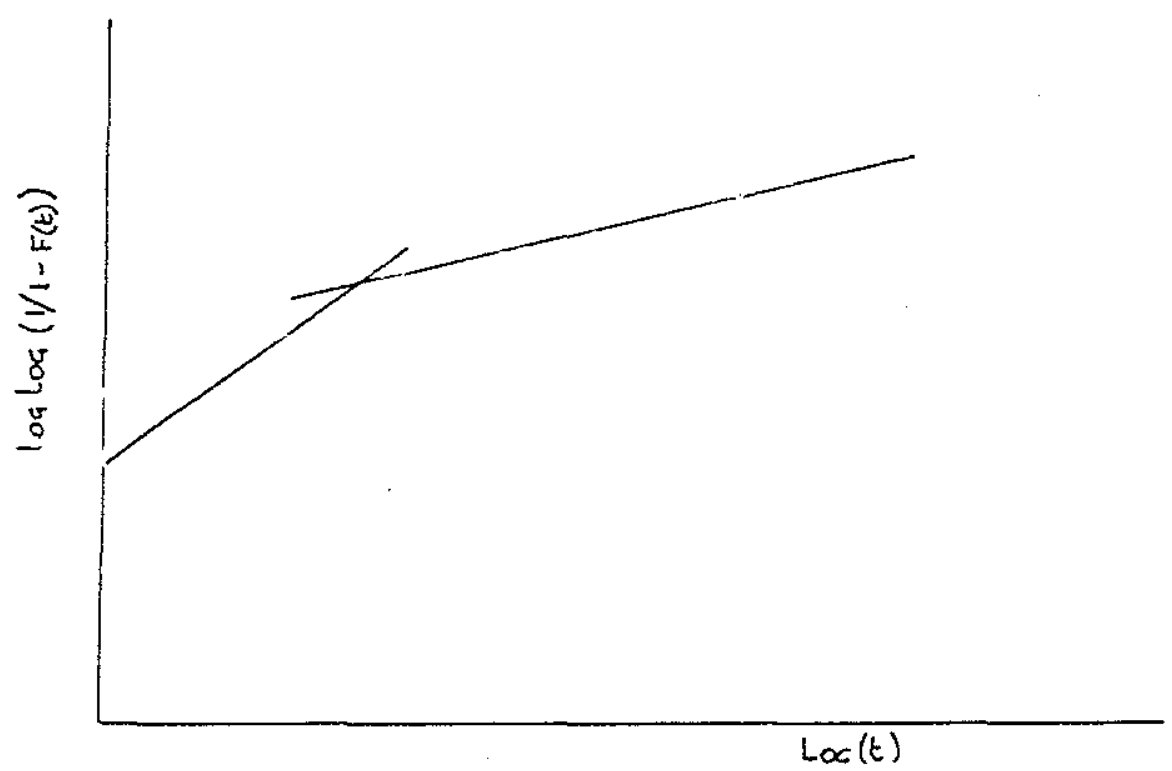

Figure 17. Wear data analysis 


\section{CONCLUSIONS}

The empirical formulae derived for normal and tangential force show good correlation with those of other researchers, basic points of similarity can be observed.

Both Tsuwa (17) and Malkin (13) conclude that there is a threshold force and this is used as a constant in their expressions.

The factors relating to metal removal were presented in a slightly different manner in that Tsuwa separated infeed and width of cut. In the derived formulae metal removal rate per unit width of wheel is used to calculate is used to calculate the forces.

The work carried out by Tsuwa only used one dress lead, but as shown in the work reported, the incorporation of the factor of dress lead is essential.

The empirical work shows good agreement with practical results and at the conclusion of the programme of research it is expected that a model will be presented that will be more acceptable to users as it will utilize values of dress lead, metal removal rate and metal removed, as opposed to values of wear flat area, contact pressure, length of arc, etc. The values proposed are those that can be readily specified, whereas those used in other derivations need to be determined by experiment.

\section{REFERENCES}

1. Lindsay, R.P., Dressing and its effect on griding performance, ASTME Creative Manufacturing Seminar, Paper MR69,568 (1969)

2. Pattison, E.J. and Chisholm, A.W.J., The effect of dressing techniques on grinding wheel wear, InternationalConference on Manufacturing Technology (Ann Arbor, Mich 1967)

3. Tsuwa, H., An investigation of grinding wheel cutting edges., Trans ASME, $J$ of Eng for Industry, 10,22 (1964)

4. Merlyn and Drukker, Getting the best out of diamond dressers and truers. Cutting Tool Engineering (1967)

5. Selby, J.E., Dressing abrasive grinding wheels with diamond tools. De Beers Industrial Diamond Division. (London)

6. Vickerstaff, T.J., Diamond dressing - its effect on work surface roughness. Industrial Diamond Review 30,260 (1970)

7. Furuichi, R., Nakayama, M. and Dei, T., Influence of dressing conditions of grinding wheel., Bull JSME 10,411 (1967)

8. Brecker, J.M., Wheel dressing variations influencing grinding., SME Paper MR 75,104 (1975)

9. Fisher, R.C., The twelve diamond dressing variables., Cutting Tool Engineering 25,5 (1973)

10. Grisbrook, H., Hollier, R.H. and Varley, P.G., Related patterns of grinding forces, wheel wear and surface finish. Int. J. of Production Research, 1,57 (1962) 
11. Rubenstein, C., The mechanics of grinding., Int J Mach Tool Des Res., 12,127(1972)

12. Koloc, J., On the wear of grinding wheels., Microtecnic, 13,45 (1959)

13. Malkin, S., The wear mechanisms of grinding wheels., ASTME - Creative Manufacturing Seminar, Paper MR 69,566 (1969)

14. Bhateja, C.P., Pattison, E.J. and Chisholm, A.W.J., The influence of dressing on the performance of grinding wheels. Annals of CIRP, 21,81 (1972)

15. Pacitti, V. and Rubenstein, C., The influence of dressing depth of cut on the performance of a single point dressed aluminium oxide grinding wheel., Int J of Mach Tool Des Res, 12,267 (1972)

16. Yoshikawa, $H$., Criterion of grinding wheel tool life., Japan Soc of Prec Eng, 1,29 (1963)

17. Tsuwa, H., Yamada, H. and Kawamura, S., An investigation of grinding wheel cutting edges., Bull of Jap Soc Precision Engineering, 10,46 (1976)

18. Reichenbach, G.S.,Mayer, J.E.,Kalpakiougki,S. and Shaw, M.C., The role of chip thickness in grinding., Trans ASME, 78,847 (1956)

19. Peklenik, J., Grinding fundamentals II, Int Conf Production Engineering Res, 196-206 (1963)

20. Peklenik, J., Contribution to the correlation theory for the grinding process., Trans ASME, J of Eng for Ind. 86,85

21. Bual, R.M., Mechanics of metal grinding with particular reference to Monte-Carlo simulation., Advances in MTDR (Pergamon) p923

22. McAdams, H.T., Markov chain models of grinding profiles., J. Eng Ind, 86,383

23. Yoshikawa, $H$. and Sata, T., Simulated grinding process by Monte Carlo method., Annals of CIRP, 16,297 ।

24. Deutsch, S.J. and Wu, S.M., Selection of sampling parameters for modeling grinding wheels., J Eng Ind, 92,667 